\title{
Cátedra de la paz: Praxis del discurso ${ }^{1}$
}

\author{
Chair of peace: Praxis of speech
}

\section{Pedro Norberto Forero López²}

\author{
Forero L, Pedro \\ miradas $\mathrm{N}^{\circ} 1$ - 2018 ISSN digital $\mathrm{N}^{\circ} 2539-3812$ Págs 144 - 161 \\ Recepción: Agosto 14 de 2017 \\ Aprobación: Marzo 7 de 2018 \\ Publicación: junio 29 de 2018
}

\section{Resumen:}

Es un artículo que pretende evidenciar la conveniencia de complementar los lineamientos de implementación de la Cátedra de la Paz, en virtud, que se considera que los establecidos por el Ministerio de Educación Nacional (MEN) no contienen las herramientas pedagógicas adecuadas para su desarrollo. La ley 1732 de 2014 y el decreto 1038 de 2015 establecen un modelo de educación para la paz restringido al ámbito escolar, bajo los presupuestos de los estándares de competencias ciudadanas y sus programas complementarios, dando lugar a que no se conjuguen acciones prácticas que permitan hacer viva la cultura de paz.

La Cátedra de la Paz tiene un sentido de territorialidad aplicado al municipio de Saboyá (Boyacá), de aplicación en sus instituciones educativas, como política púbica de educación.

Los presupuestos de la ética discursiva se convierten en un modelo complementario para abrir espacios al diálogo, y en un escenario óptimo para la construcción de una convivencia pacífica a partir de acciones dialógicas. Sus fortalezas consisten en la capacidad de ofrecer múltiples elementos que facilitan relaciones intersubjetivas, que permiten el reconocimiento, la tolerancia, la diversidad y la pluralidad, desde una posición imparcial, mediante los actos del habla, consensos plenos de validez y una acción del otro, que facilite el reconocimiento, la diferencia y la diversidad como elementos estructurales para el desarrollo y garantía de los derechos humanos y la convivencia pacífica.

\footnotetext{
1 Este artículo de reflexión tiene relación con el trabajo de grado adelantado para optar al título de Magíster en Derechos Humanos de la Universidad Pedagógica y Tecnológica de Colombia (-UPTC- seccional Chiquinquirá). Es un trabajo individual que tiene fundamento con la implementación de la Cátedra de la Paz en el municipio de Saboyá, con fundamento en la ética discursiva como modelo complementario de los lineamientos del gobierno nacional, a partir de la ley 1732 de 2014 y del decreto 1038 de 2015.

2 Estudiante de la Maestría en Derechos Humanos de la UPTC (seccional Chiquinquirá); abogado de la Universidad Autónoma de Colombia; especialista en Derecho Administrativo de la Universidad Militar Nueva Granada; actualmente personero municipal de Saboyá. pedroforerolopez@gmail.com
} 
Palabras claves: Cátedra de la Paz, Saboyá, ética discursiva, presupuestos práxicos, lineamientos de implementación.

\section{Abstract}

This paper aims to show the benefit of complementing the Chair of Peace guidelines, by virtue of the fact of those which are established by the Ministry of National Education (MEN), does not have suitable pedagogical tools for the correct development of the Chair of Peace.

Law 1732 of 2014 and decree 1038 of 2015 establishes an educational model for peace which is limited to schools environment, and to the budgets of citizen competencies standards and their complementary programs, having as a result of this, difficulties in the possibilities of combining different actions which can allow giving life to the peace culture.

The Chair of Peace has a territoriality sense applied to the Saboyá municipality (Boyacá), which aims to be implemented in its educative institutions as a public policy of education.

The budget of the discursive ethics becomes a complementary model to open dialogue scenarios, being appropriated for the construction of peaceful coexistence, starting from dialogic actions. Its strength is directly related to the capability to implement a variety of tools that can facilitate the intersubjective relationships, allowing recognition, tolerance, diversity, and plurality from impartial positions, through speech acts, full consensus of validity and acts from participants that facilitates recognition, differences and the diversity as structural elements for the appliance and guarantee of human rights and peaceful coexistence.

Keywords: Chair of the Peace, Saboyá, discursive ethics, budgets, guidelines of implementation.

\section{Introducción}

La ética discursiva es un modelo de vida que comprende múltiples presupuestos práxicos que la convierten en facilitadora de formas de vida que transforman la conciencia de los colectivos a partir de sus postulados de razonabilidad, validez, veracidad, ausencia de coacción, igualdad, corrección, posicionamiento moral alter y capacidad de crítica y reflexión, para construir consensos fuente de normas de validez. De esta manera, es un dispositivo complementario para la promoción de los derechos humanos, en virtud a la capacidad de facilitar que sus normas de validez permitan la posibilidad de transformar los conflictos en situaciones de convivencia pacífica, a partir del reconocimiento, la tolerancia, la diversidad y el respeto, no como simples valores, sino como formas materiales de vida.

Se comienza con el esbozo de la teoría de paz, estableciendo una relación entre el modelo implementado en Colombia y los programas establecidos desde el seno de las Naciones Unidas (UNO) y la Unesco. Luego, se avanza sobre los contenidos de la ética discursiva, su fundamentación y su práctica, y se recoge la postulación de los prepuestos práxicos de la ética discursiva, en un análisis somero para evidenciar sus características, denotando la viabilidad y fortalezas en los entornos académicos de las instituciones educativas del municipio de Saboyá. El análisis toma como asidero 
los proyectos educativos institucionales (PEI) y los avances que hasta este momento han realizado las instituciones educativas del municipio en la implementación de la Cátedra de la Paz. Finalmente, se sientan algunas conclusiones sobre la relación de los lineamientos oficiales y los presupuestos práxicos discursivos.

El aporte de la ética discursiva, mediante sus presupuestos prácticos, facilita que los agentes de aprendizajes puedan, con base en estos, trascender hacia nuevas formas de aprendizaje y hacia la convivencia, mediante acciones vivificadoras en los distintos contextos sociales y culturales. La ética discursiva logra su cometido, como dinamizadora de las formas de vida, mediante el diálogo, la argumentación, los actos del habla y las representaciones sociales.

Teniendo en cuenta que la Cátedra de la Paz llega a nuestro contexto social y cultural como una política pública en educación para construir la cultura de paz, es necesario recurrir a un modelo ético que facilite el tránsito de la cultura de violencia hacia la cultura de paz. Debe ser un dispositivo que pueda complementar la propuesta gubernamental, para generar la capacidad de permear la conciencia de los colectivos y lograr una verdadera transformación en las formas de solución de los conflictos y la superación de las violencias.

Los lineamientos de la Cátedra de la Paz establecidos en la política pública tienen una connotación restringida a los estamentos educativos, cuando la educación para la paz exige mayor integración entre los contenidos y las prácticas para afianzar los aprendizajes. Como los escenarios escolares corren el riesgo de ser repetidores de contenidos vacíos, se requieren estrategias que faciliten la reflexión y la crítica sobre la incidencia y la transformación de la vida de los aprendices en el mundo de vida vital.

De esta manera, por sus características formales y procesuales, la ética discursiva cuenta con las herramientas suficientes para avanzar hacia una cultura de paz mediante la formación de sujetos integrales que puedan asumir roles práxicos en la construcción de sus proyectos de vida. Su praxis es la vivencia del conocimiento, que se adquiere en la correlación sujeto-objetoalter-objeto-sujeto. En ese sentido, la ética discursiva facilita a los sujetos capacidades para establecer relaciones interpersonales propiciadoras de diálogos para construir consensos válidos.

\section{La cátedra de la paz: educación y cultura de paz}

La violencia en Colombia tiene sus orígenes en distintas causas. Para Zuleta (2006), las diferencias partidistas entre conservadores y liberales se destacan entre las causas más sobresalientes de la violencia, posiblemente agudizada por los efectos de la consolidación de la nación (pp. 60-62). También pudo tener incidencia la constitución del pueblo, como una resistencia de la clase campesina ante la fuerza avasalladora del desarrollo en el sistema de producción capitalista. Se cree además que la propiedad de la tierra es otro elemento generador de violencias. De tal suerte, durante todo el siglo XX y lo que va corrido del 2017, la violencia no ha cesado, con múltiples causas como la subversión, el paramilitarismo, las organizaciones criminales comunes y la delincuencia organizada. 
El gobierno de Colombia y el Congreso de la República, ante la necesidad de establecer una cultura de paz y de acatar los lineamientos establecidos por la comunidad internacional —especialmente de la Unesco y el desarrollo de la Constitución Política de 1991—, desde 1998 estableció la educación en ética y valores y otros proyectos, como los estándares en competencias ciudadanas adoptados desde el año 2004.

Después, a partir del año 2011, debido a las expectativas por el comienzo de los diálogos de paz con las Fuerzas Armadas Revolucionarias de Colombia (FARC), se inició en el país un proceso de implementación de normas encaminadas hacia el posconflicto. En ese sentido, entre otras normas, se promulgaron: la ley 1448 de 2011, relacionada con los derechos de las víctimas del conflicto; la ley 1620 de 2013, reguladora de la convivencia escolar; la ley 1622 de 2013, mediante la cual se adoptaron políticas de participación de las juventudes, con la creación de las plataformas y los concejos de juveniles, y la ley 1618 de 2013, que protege los derechos de las personas diversamente hábiles.

Es en ese contexto que aparece la Cátedra de la Paz, con la expedición de la ley 1732 de 2014 y del decreto 1038 de 2015. Con la promulgación de estas disposiciones se plantea una apuesta política orientada a crear una cultura de paz. Se entiende, en ese sentido, que la paz nace en las familias, en los contextos sociales y en las instituciones educativas; asimismo, que la violencia no es un fenómeno natural, sino el producto de la acción social de los seres humanos. La propuesta se orienta hacia un modelo de educación pública encaminado hacia el desarrollo sostenible, aspecto que le da un sentido ecológico y ambiental, como una forma de vida sistémica.
El informe del MEN (2001, p. 7) establece que la transformación de la educación está encaminada a que las personas ejerzan sus derechos y facultades, con fines de participación, autonomía, diversidad étnica, lingüística y cultural, en procura de construir la identidad nacional. Dichos derechos pueden ejercerse a través del conocimiento de los consensos sociales, mediante espacios de participación para la toma de decisiones.

Las facultades democráticas de paz tienen asidero en procesos formativos, concertados con las comunidades o mediante los gobiernos escolares. Su concreción está sujeta a las acciones realizadas en el contexto de los consejos directivos, las juntas de educación, el personero estudiantil, los comités de convivencia o las escuelas de padres, ya sea dentro de la comunidad académica o en el seno de las comunidades.

De esta manera, como lo indica el informe del MEN, se propone fortalecer los gobiernos escolares como ámbitos de formación y participación social, como espacios de fundamentación en valores y prácticas democráticas, y realizar otras acciones de mediano y largo plazo mediante el ejercicio de objetivos programáticos, como la ampliación de la cobertura y el mejoramiento de la calidad de la educación (2001, p. 4).

La Cátedra de la Paz, como modelo de educación para la paz, tiene su precedente en el seno de las ONU, en especial, en su organismo especializado paras la educación, la ciencia y la cultura, la Unesco, que desde 1948 emprendió la acción de promover la teoría de Escuela Nueva. A través de múltiples instrumentos internacionales, ha hecho un desarrollo que 
ha contado con varias etapas: la primera, la concepción de políticas de educación en forma general; la segunda, la investigación para la educación para la paz, y la tercera, la creación de una cultura de paz. Es lo que Jares denominó las "olas de la paz", como una clasificación de cuatro etapas (Acodesi, 2003, pp. 19-20).

En la contemporaneidad, las etapas de las investigaciones para la paz (López, 2011, p. 87-88) aparecen clasificadas en tres periodos: la primera, de 1930-1959, especialmente la concepción de ausencia de violencia o paz negativa; la segunda, de 1959-1990, donde se creó el Instituto para la Paz de Oslo, haciendo énfasis en la paz positiva, relacionada con la superación de las necesidades básicas para la subsistencia de una persona, y la tercera, de 1990 hasta la actualidad, con fundamento en el concepto de violencia cultural.

La teoría de la paz cultural se relaciona con la acción humana, porque es una herramienta que permite que las partes resuelvan los conflictos favorablemente. No obstante, como dispositivo constructor y transformador de formas distintas de aprehensión del mundo de la vida, necesita de un imaginario social dentro de un contexto histórico-material. Esto en cuanto a que su creación y desarrollo están condicionados al contexto meramente escolar, por tanto, se requiere de una cultura ajustada a los intereses de los afectados, en un espectro histórico-espacial más amplio.

El planeamiento de esa posición, a pesar de parecer utópico por la persistencia de causas y efectos relacionados con las ideologías y culturas enraizadas en costumbres que no se permean tan fácilmente, es una propuesta en escena desde los imaginarios de un giro progresivo y constante en las prácticas sociales y de vida, para formar la conciencia social hacia una forma distinta de pensar, sobre la asunción de los conflictos y su solución.

La cultura de paz puede ser un proceso lento (Sánchez, 2016, p. 79) que conlleva un cambio de la forma de pensar, que es precisamente la manera como se da el giro cultural. La concepción que promueve la asunción positiva de los conflictos ofrece una alternativa para que sirvan para construir modos de convivir sin tener que recurrir a la violencia (Jares, 2002, pp. 80$82)$.

El trabajo en el aula no es suficiente ni puede mantenerse puro. El riesgo de contaminación con el ambiente familiar y social es inminente, ya que los constructos escolares se interrelacionan y afectan positiva o negativamente con su desarrollo cultural (Jares, 2002, p. 80). Si aceptamos que la educación para la paz es un elemento favorable y determinante para la cultura de paz, debe acudirse a elementos estructurales de los procesos de enseñanzaaprendizaje que permitan la elaboración de estrategias de aprendizaje eficaces para generar cambios en las formas de vida de las personas. No solo debe recurrirse a los métodos convencionales, que se agotan en los currículos de las instituciones educativas, sino que al proceso deben integrarse los contextos sociales, desde la familia, la sociedad y el docente.

\section{Contenido y fundamentación de la educación para la paz en Colombia}

El modelo colombiano de la educación para la paz, a pesar de incurrir en el desacierto de limitarla al contexto académico como 
una asignatura, según la reglamentación del gobierno nacional mediante el decreto 1038 de 2014 (art. 1) Promueve un cambio cultural en la educación, especialmente acciones desde la sociedad civil de manera pragmática. Se plantea desde esa perspectiva el mandato de la Constitución Política (1991) de promover la educación, en consideración a la paz como derecho fundamental y como deber (art. 22, 95, pp $6)$.

Según Rodríguez (2016, pp. 8-9), la educación para la paz se fundamenta en unos contenidos éticos, que tienen como objetivos: el desarrollo de la autonomía de los estudiantes; la posibilidad de construir proyectos de realización personal, y el trabajo en ambientes escolares alrededor de un proyecto ético. De esa manera, se busca fortalecer propósitos comunes e individuales, procurando contrarrestar la doble moral.Asimismo, también se pretende construir la escuela como un proyecto multicultural para el reconocimiento de la diferencia (2008, p. 7) la pluralidad y la singularidad. Todo esto se alcanza mediante competencias y capacidades para asumir los valores y actitudes dialógicas y comunicativas con sentido crítico, juicio y racionamiento moral y sentimientos de vínculo y empatía (Reyes, Lozano, Vargas, Bayona, y Molina, 1998, pp. 1314). De esta manera, se asume el propósito de la vida como proyecto político, donde la ética es el valor para actuar, dialogar y reflexionar sobre el significado de la vida misma y las imágenes que percibimos del mundo (Reyes, et al., p. 17).

\section{La cátedra de la paz en el municipio de Saboyá}

En el municipio de Saboyá existen seis instituciones educativas (IE) públicas y una privada, cada una con orientaciones particulares (Tabla 1):

Tabla 1. Instituciones educativas del municipio de Saboyá

\begin{tabular}{|c|c|c|}
\hline $\begin{array}{c}\text { Institución } \\
\text { educativa (IE) }\end{array}$ & Ubicación & Orientación \\
\hline $\begin{array}{l}\text { Normal } \\
\text { Superior }\end{array}$ & Área urbana & $\begin{array}{l}\text { Orientación } \\
\text { pedagógica. } \\
\text { Cuenta con } \\
\text { un programa } \\
\text { complementario } \\
\text { de formación de } \\
\text { docentes en cuatro } \\
\text { semestres }\end{array}$ \\
\hline IE San Marcos & $\begin{array}{l}\text { Vereda Mata } \\
\text { de Mora }\end{array}$ & $\begin{array}{l}\text { Orientación agrícola. } \\
\text { En atención a la } \\
\text { vocación agrícola } \\
\text { de la vereda, } \\
\text { especialmente de } \\
\text { papa y mora }\end{array}$ \\
\hline $\begin{array}{l}\text { IE José María } \\
\text { Córdoba }\end{array}$ & $\begin{array}{l}\text { Vereda } \\
\text { Merchán }\end{array}$ & $\begin{array}{l}\text { Orientación hacia la } \\
\text { formación técnica }\end{array}$ \\
\hline IE Juan Pablo II & Vereda Molino & $\begin{array}{l}\text { Orientación hacia la } \\
\text { educación ambiental }\end{array}$ \\
\hline IE San Isidro & $\begin{array}{l}\text { Vereda Puente } \\
\text { de Tierra }\end{array}$ & $\begin{array}{l}\text { Orientación hacia la } \\
\text { formación técnica en } \\
\text { sistemas }\end{array}$ \\
\hline IE Garavito & $\begin{array}{l}\text { Centro } \\
\text { poblado del } \\
\text { mismo nombre }\end{array}$ & Orientación social \\
\hline $\begin{array}{l}\text { IE Nueva } \\
\text { Inglaterra } \\
\text { Campestre* }\end{array}$ & $\begin{array}{l}\text { Vereda Puente } \\
\text { de Tierra }\end{array}$ & -- \\
\hline
\end{tabular}

Fuente: elaboración propia.

Estas instituciones educativas se encuentran actualmente en la fase de 
implementación de la Cátedra de la Paz, por tanto, su desarrollo apenas está condicionado a la implementación de sus PEI y a la formalización de los planes de área en algunas instituciones. La Normal Superior adelanta algunos programas significativos como los Comités de Aula en los diecisiete cursos que contiene, como un mecanismo encaminado a la solución pacífica de los conflictos desde el seno mismo de la pequeña comunidad, en una relación de pares sin roles de autoridad y de responsabilidad recíproca, empoderados de la acción civil para la convivencia en comunidad. La IE José María Córdoba igualmente implementó un modelo similar en todos sus cursos, denominado "mediadores de paz".

Las autoridades públicas adelantan esfuerzos encaminados a fortalecer los procesos de las IE. La Personería Municipal, con el apoyo de la Alcaldía, adelanta un proceso de sensibilización en la comunidad académica mediante la creación de un Comité de la Cátedra de la Paz que integra a las escuelas con entornos sociales, como las Juntas de Acción Comunal, las asociaciones de padres de familia y las comunidades rurales.

\section{Presupuestos práxicos de la ética discursiva válidos para la cátedra de la paz}

La doctrina y fundamentación de la educación para la paz se adhiere a la pedagogía de Piaget y Kohlberg y en alguna medida a la pedagogía de Paulo Freire (Freire, 2006, p. 24-25), esto es, a la reflexión crítica sobre la práctica como una exigencia de la relación teoría/práctica, donde no hay docencia sin discencia. Es una propuesta práxica de la vida educativa en la que la experiencia está ligada al desarrollo del conocimiento de manera integral y en relación con todos los saberes necesarios para la formación de un individuo que no se comporta como tal, sino que tiene la capacidad de involucrarse en un proyecto de interacción dialógica con los demás y de aceptación de dicha condición, como producto del reconocimiento y la comprensión.

Por lo anterior, se debe buscar un modelo instrumental que pueda aportar si no todos, sí un buen número de herramientas dialógicas, constructivas e integradoras de los métodos y estrategias para la formación autocrítica y autorreflexiva que se procura. En ese sentido, la acción comunicativa que fundamenta la ética discursiva es el modelo que aporta con sus presupuestos práxicos los dispositivos de mayor capacidad de proyección en la construcción de la cultura de paz, que invoca y desarrolla la Cátedra de la Paz.

No sobra advertir que no es una camisa de fuerza ni es la única posibilidad. Esta propuesta solamente surge como complemento, especialmente atendiendo los lineamientos sobre los cuales se implementa esta asignatura encaminada a fortalecer la cultura de paz.

Los presupuestos práxicos de la ética discursiva representan la forma de vida en el mundo de la vida de las comunidades escolares, sociales y familiares del municipio de Saboyá. Estos presupuestos son falibles por su condición histórica, enmarcada en las formaciones culturales y las prácticas sociales; además, la historia les imprime una connotación de relatividad porque ninguna de las ciencias sociales es infalible y definitiva (Ruiz, 2007, p. 
94). La relatividad está condicionada por las evidencias con las cuales se pretenda reconstruir la verdad. De esta manera, no se puede pensar en pedagogías trascendentales sin las cuales no se pueda construir nuevos aprendizajes de paz.

Según Garcés (s.f.), la ética discursiva tiene unos vectores o presupuestos que dan fundamento de su teoría:

1) La Universalidad, como posibilidad de cohabitar en una mayor diversidad ecológica y de diálogo con otras culturas. 2) La autonomía, como capacidad de autorregulación interna de manera consciente y libre. 3) La actividad de procesamiento de información. 4) Por último, la diversidad integrada, mediante la cual se reconoce la fuerza evolutiva en el universo de la especie humana. Especialmente, la dignidad y la posibilidad misma de racionalidad, que se desarrolla a través del lenguaje (p.345).

En términos generales, la educación facilita la formación del individuo en prácticas de solidaridad social, resolución creativa y productiva de los conflictos, participación social y convivencia ciudadana. En tal sentido, según Reyes, et al. (1998, p. 59), el MEN propone fortalecer los gobiernos escolares como ámbitos de formación, de participación social, de fundamentación de valores y prácticas democráticas, aptitudes que se pueden lograr mediante la creación de unas condiciones mínimas que posibilitan el diálogo (Valencia, 2004, p. 2). Al respecto de esas condiciones, Valencia indica que son:

Primera, el diálogo como reconocimiento del valor y la legitimidad del interlocutor; segunda, la actitud crítica frente a la propia posición que se trata de sustentar, y la tercera, es el reconocimiento de los actores que exigen unas reglas mínimas, universales y abstractas. Estas condiciones se traducen en la condición fundamental sobre la cual se alcanza las verdaderas relaciones de convivencia: el diá$\operatorname{logo}$ (p. 3).

Desde esa postura, la acción dialógica implica que el discurso es una relación entre pares, una presunción de igualdad, de horizontalidad, en la medida que es un binomio: agente de aprendizajes. Además, se requiere que la relación dual se produzca entre sujetos, esto es, entre personas que tienen la capacidad de asumir una posición de reconocimiento del contradictor a partir de postulados de respeto y tolerancia, como acción alter, que facilitan la comprensión de las demás acciones, representaciones y actos del habla con los que los sujetos establecen las relaciones intersubjetivas.

Desde allí, la acción dialógica se entiende como la acción fundada en la práctica positiva de asumir las consecuencias de la postura asumida y de aceptar los efectos del consenso (Habermas, 1994, p. 157). Esa realidad concreta se ejecuta a partir de la praxis y la pragmática: la primera como realización de la teoría en las prácticas de vida y la segunda como producción 
de significados a partir de los actos del habla mediante códigos lingüísticos y las representaciones sociales (Ruiz, 2007, pp. 44-45). Son formas de concebir y asumir la relación práctico-teórica de las acciones y de las vivencias mismas.

El discurso es una praxis mediante la cual se introducen de manera creativa convenciones semánticas en un sistema de lenguaje. De esta manera se logra superar la relación sujeto-objeto para trascender al fenómeno de la alteridad, esto es, desde la perspectiva del observador (Habermas, 2010, pp. 604-605).

Esta fenomenología se presenta en las relaciones de los actos comunicativos para subjetivar el mundo objetivo, donde el hablante, dice Habermas, sale al encuentro del oyente planteándose relaciones recíprocas; ese mundo subjetivado se transforma luego a través de las acciones en mundo objetivo social. Se forma un conjunto de actos comunicativos de múltiples mundos objetivos, subjetivos y sociales, convirtiéndose en un mundo cultural, que sucesiva y continuamente se transforma en mundos sociales nuevos. Estos mundos se entrecruzan con el aspecto teleológico y el aspecto comunicativo a través de relaciones intersubjetivas (Habermas, 2010, p. 607) que no pueden quedar reducidas al culturalismo del mundo de la vida. Por el contrario, tienen que ser la consolidación de los proyectos de vida individuales, contenidos coherente y armónicamente en las acciones sociales, como producto de acciones humanas plenas de sentimientos e historias verdaderas de vida (Habermas, pp. 616 y 617).

Este planteamiento de Habermas implica que el discurso es contentivo de una semántica, pero con vocación de acción y de alteridad. Es un discurso práxico que goza de los presupuestos de validez porque en él los participantes tienen verdaderas pretensiones de diálogo hacia el consenso, sin importar que lo logren o queden frustrados, porque el disenso es en esencia una posibilidad de acuerdo. Debe ser cierto, público, libre de coacciones y razonable.

Todos esos presupuestos son objetivos y materiales, fuera del contexto de la relación sujeto-objeto. Los intervinientes no procuran intereses personales ni individuales, toda vez que sus acciones no son el resultado de una acción estratégica o instrumental, sino que son una acción social en cuanto imperativo superior independiente de las personas (alter). Por tanto, el discurso es acción y no necesariamente acción causal. Debe ser acción social, como una superación del mundo material de carácter meramente natural, mediante la transición a la etapa convencional de la acción (Habermas, 1994, p. 189) en el resultado de las relaciones intersubjetivas: en una relación sujeto-sujeto.

La ética discursiva, por su capacidad autocrítica y autorreflexiva, posibilita desde la teleología de los discursos la formación de las normas que han de regular las relaciones intersubjetivas de los actores intervinientes. Estas tienen mayores ventajas para construir una cultura de paz basada en el reconocimiento, el respeto y la tolerancia, porque los consensos son fuente de las normas universales. Y son universales no porque lo sean per se o porque tengan vocación de inmutabilidad, sino porque son el producto del consenso de todos los participantes. Todos los actores tienen una intencionalidad encaminada a la 
formación del discurso con conocimiento de sus fines, efectos y consecuencias de resultado. No existen categorías valiosas como consecuencia objetiva o material; no hay derechos naturales consecuentes de la naturaleza ni valores preestablecidos.

Los lineamientos oficiales definen las competencias comunicativas como las habilidades necesarias para establecer diálogos constructivos con las demás personas. La capacidad de escuchar de manera activa. De alguna manera, el planteamiento gubernamental sale al encuentro de la propuesta planteada en este artículo en relación con la acción comunicativa de corte habermasiano.

Tienen asidero las anteriores consideraciones porque la ética discursiva se relaciona de manera directa con varios componentes de la Cátedra de la Paz. El andamiaje de implementación se fundamenta en la construcción de diálogos en todos los contextos para construir la cultura de paz. Es una postura de garantía de los derechos humanos, el fortalecimiento de la democracia y el reconocimiento de la dignidad humana, cuyos postulados son similares a la ética discursiva. Esta debe corregir la carga moral y material, mediante las normas que se produzcan en los discursos dialógicos válidos como consecuencia de los principios de validez (Principio D) y de universalidad (principio U), (Habermas, 1994, p. 142-144).

En ese sentido, por su condición formal y procesual, la propuesta holística (Galtung, 2003, p. 7) resulta adecuada para construir la paz. Ello se debe a que el diálogo es extensivo a todas las formas de discurso en la familia, la escuela y en el entorno de la sociedad civil, organizada y participativa.
Articula dichos escenarios democráticos para generar cambios culturales ostensibles como un todo (Cohen y Arato, 2000, pp. $26,43,53)$.

De otro lado, la ética discursiva facilita que los sujetos acepten el ellos, el nosotros y los demás, como sujetos que no se posicionan en una simple relación de sujeto-objeto, sino que además de las relaciones intersubjetivas hay unos sujetos observadores (alter) de la convivencia, que piensan y actúan a partir de ella, como la forma de vida adecuada para aprovechar el entorno y la naturaleza y así poder coexistir como seres sociales (Habermas, 2008, pp. 82-83, 88-96, 375).

Respecto a las relaciones sociales de reconocimiento, que demandan el respeto por la diversidad, la pluralidad y la tolerancia, la ética discursiva también cuenta con presupuestos que sirven de base primordial para lograr relaciones intersubjetivas (Giménez, 2008, p. 7). Según lo anterior, cuando el actor del diálogo se despoja de los intereses meramente instrumentales o estratégicos luego que ha logrado hacer una ponderación del conflicto en la posición del observador, tiene la posibilidad de entender y asumir que existen diferencias de criterios y de actores.

Todos en el discurso admiten que son iguales, que tienen las mismas posibilidades y que, en proporción, igualmente asumen las responsabilidades. Es un mecanismo que facilita llegar a relaciones interculturales ausentes de roles de discriminación y de exclusión, porque permite que todos, en igualdad de condiciones, estén en situación de inclusión, respeto, asimilación y pluralismo. 
Cuando el diálogo permite la formación de consensos garantes de la dignidad humana, las libertades y la igualdad, resultan garantizados y desarrollados en su mayor esplendor los derechos humanos. Otras éticas pueden ser útiles pero no resultar coherentes con el modelo propuesto. Las éticas normativas coartan la crítica y la reflexión porque el deber ser no permite razonar ni facilita el reconocimiento y la aceptación, en virtud a que todo ya está dispuesto y ordenado, de tal manera que lo único que resta es cumplir. La ética material o de los valores, igualmente, determina que todo lo tiene valorado, ponderado y categorizado; por ello, es contra natura asumir una posición distinta a su concepción.

\section{La cátedra de la paz en Saboyá a partir de los presupuestos práxicos de la ética discursiva}

Los PEI de las siete instituciones educativas del municipio de Saboyá están medianamente adecuados a los lineamientos de implementación de la Cátedra de la Paz. Todas las IE se esfuerzan por formular propuestas que recojan la mayor cantidad de contenido de la ley 1732 de 2014 y del decreto 1038 de 2015; en especial, se propone el diálogo con el centro de las posibilidades de convivencia y de cambio de la cultura de las comunidades.

Esta invitación dialógica motiva a colocar sobre la mesa la propuesta de una acción comunicativa (dialógica). La iniciativa implica un conjunto de acciones de comunicación para llegar a acuerdos (consenso-disenso) encaminados al fortalecimiento de la convivencia pacífica, desde un posicionamiento de la educación moral (Ruiz, 2007, pp. 65-66), atemperado por el condicionamiento de una ética formal y procesual que aporte las herramientas para la construcción de acciones críticas, reflexivas, para comprender la existencia, su relación con el universo y la aceptación de la relatividad de condición humana en el ejercicio y goce de los derechos respecto al cumplimiento de los deberes.

La ética discursiva es una ética racional y responsable. De esa manera, la paz no se transporta a un escenario de meras expectativas, sino que se traduce en acciones concretas de reconocimiento, tolerancia, diversidad, pluralidad, justicia y desarrollo. Su facticidad implica la posibilidad de asumir muchos de los procesos de enseñanza-aprendizaje en situaciones práxicas, por ejemplo, en la educación ambiental. En el sistema educativo colombiano existen varios programas de educación ambiental en los cuales podrían integrarse los estudiantes. Entre ellos están el Comité Interinstitucional de Educación Ambiental; los proyectos productivos escolares; CicloReciclo; Vigías Ambientales de la CAR, entre otros.

A través de sus presupuestos de razonabilidad, crítica y reflexión y mediante los actos del habla y las representaciones sociales, la ética discursiva facilita la asunción de los contenidos y las prácticas sociales. Todo esto se presenta durante la construcción del PEI, proceso que cuenta con la participación de la comunidad académica en general, entendida como el cuerpo de docentes, los padres de familia, la comunidad y los estudiantes. Para ello, los participantes necesitan saber cuáles son los contenidos y prácticas que desde su entorno social les interesan, y cuáles son esas prácticas educativas que quieren 
poner en marcha, según el presupuesto de publicidad. Asimismo, ya en el escenario del proceso de enseñanza-aprendizaje, el docente tiene que concertar constantemente las prácticas educativas con sus alumnos. En ese sentido, el modelo discursivo entra a jugar un papel destacado, ya que los PEI no pueden ser impuestos.

Estos aspectos conllevan que los estudiantes tomen conciencia de sí mismos frente a sus compañeros, hecho que posibilita que elaboren una abstracción de ese mundo real ya abstraído. Dicho de otra manera, el educando convierte la comunidad de comunicación real, es decir, a partir del diálogo, transforma la comunidad en la que vive - su entorno cultural- en un mundo de comunicación ideal, con base en los presupuestos de validez. El estudiante lo logra una vez supera la etapa fenomenológica y la convierte en conceptos, juicios y teorías, es decir, en un posicionamiento subjetivo o moral, y una vez subjetivado el mundo de la vida, redundará en acciones concretas de paz. La ética del discurso es pues una ética que deconstruye y construye acciones que facilitan el posicionamiento moral.

Después de cumplir ese proceso de reflexión, autorreflexión y autocrítica y tras determinar acciones concretas en el mundo de la vida convertidas en una cultura de paz, el aprendiz adquiere en esa dialéctica de acción-afirmación-acción aprendizajes significativos y complejos de acciones de paz, sin tener ahora que recurrir al almacenamiento de contenidos, o como observa Freire, se evita el "aprendizaje bancario". Así, de esta manera se concede mayor capacidad para la solución pacífica de los conflictos y se abre una posibilidad para eliminar la violencia como práctica social.
Siguiendo a Kohlberg en sus etapas del desarrollo moral, debe agregarse que existen condiciones especiales y concretas. A partir de esa postura, las etapas del desarrollo moral pueden ajustarse a la edad del actor o considerar otras circunstancias, como sucede con las personas en condición de discapacidad cognitiva, con aquellas provenientes de entornos sociales poco favorables, los niños de edades menores, etc. Si se construye esa categorización de las condiciones de validez de los consensos, pueden darse consensos básicos, estructurados y universales.

Los consensos básicos son aquellos acuerdos simples donde los actores no intervienen con el pleno de los requisitos de la acción comunicativa, sino que entienden solamente que están en la posición de dialogar y de construir acuerdos. En los consensos estructurados ya los actores deben conocer, aunque de manera incipiente, la estructura de la acción comunicativa y reconocer moralmente que están en la condición de producir consensos de validez. Entra en juego aquí la posición ética discursiva porque comprende una acción ética de las personas y la responsabilidad de su consenso. Los consensos universales concurren cuando ya se está en posición de producir normas de validez universales que se convierten en un modelo ético, es decir, se avanza del posicionamiento meramente ético-moral del sujeto para asumir la acción ética plena de alteridad social.

A medida que avanza con mayor capacidad dialógica, porque cuenta con los insumos para construir diálogos bajo presupuestos de validez, el actor llega a un grado tal de abstracción que representa el mundo exterior con una exactitud muy 
cercana a la verdad. Es en ese momento cuando formula juicios de validez que se convierten en normas que se exteriorizan en su conducta, volviendo a transformar el mundo exterior. Durante todo ese proceso, el estudiante va construyendo consensos básicos, estructurados $\mathrm{o}$ universales, según su desarrollo moral y su estado de formación ética.

De esta manera, la ética discursiva va desarrollando un número considerable de presupuestos práxicos en cuanto concilian la teoría aprendida de la experiencia y la convierten en experiencia propia. Es esta capacidad de transformación la que permite que, como modelo ético, la ética discursiva sea eficaz para construir una cultura de paz, puesto que, valida de herramientas pedagógicas adecuadas, como el constructivismo, las pedagogías de la liberación y de la autonomía, pueda llegar a consolidar formas de pensamiento y de acción de constante transformación, a medida que se van haciendo más continuas y permanentes.

Habermas reconoce que la ética discursiva puede emplearse en competencia con otras éticas, por ejemplo, en la descripción de concepciones morales y jurídicas empíricamente preexistentes. También se puede introducir en las teorías del desarrollo de la conciencia moral y la jurídica, tanto en la esfera de la evolución sociocultural como en las de la ontogénesis, haciéndola de este modo accesible a una comprobación indirecta. Por tanto, advierte Habermas que los discursos prácticos están sometidos a limitaciones que es preciso tener en cuenta, especialmente en relación con la autocomprensión fundamentalista.
Se tiene entonces que la ética discursiva propone dos momentos para construir su articulación con el mundo de la vida: uno de carácter conceptual y otro de relevancia práctica (Ruiz, 2007, p. 19). El segundo momento, según el mismo Ruiz, busca establecer cómo la educación, de manera abierta, flexible y precisa permite comprender los fenómenos educativos y la responsabilidad moral y política. Sin duda, es un reto que la ética discursiva debe afrontar para poder ser verdaderamente procedimental y poder generar acciones concretas en la vida de las personas.

Como lo advierte Ruiz (2007, p. 19), Habermas y Apel se han ocupado de su fundamentación, pero las prácticas pedagógicas ofrecen problemas distintos y diversos, donde se entronizan con los contextos políticos, sociales, morales, académicos y de todo orden, con lo cual, podrían transformar la realización, intervención y acción de los sujetos en su interrelación. La propuesta se orienta a ocupar el escenario de la praxis a partir de la cual podrían asumir una actitud realizadora o performativa (Ruiz, 2007, p. 34), de tal suerte que puedan afrontar el problema desde la posición imparcial del observador. Hay un rompimiento con la mera subjetividad (no implica abandono total de lo subjetivo) para poder lograr una abstracción por parte del sujeto cognoscente, como una actividad científica.

Otro presupuesto práxico es el posicionamiento moral, entendido como dispositivo que permite interiorizar la percepción del mundo objetivo, ya sea a través de los actos del habla o de las representaciones sociales. Si ese proceso se cumple solo con base en los meros contenidos, servirá apenas para una 
simple formación moral que no garantiza que trascienda al mundo material desde las acciones éticas. La trascendencia ética se logra mediante conductas, comportamientos y acciones.

En ese sentido, la ética discursiva comienza a jugar un papel trascendental porque en su acción procesual aporta los insumos para que el sujeto cognoscente interactúe dialógicamente entre los tres contextos, esto es, a medida que fortalece su formación moral como subjetivación del mundo de la vida, puede, a partir de la crítica y la reflexión, valorar ese mundo fenomenológico con respeto a lo construido subjetivamente. A la vez, posicionado ahora el sujeto en la condición de observador imparcial, su alteridad le permite ser objetivo y, desde esa condición, construir la cultura de paz como acción y no como norma.

Es así como el discurso práctico se instituye como procedimiento para la comprobación de la validez de normas a partir de los requisitos de la argumentación de los actos del habla, y no como un procedimiento de producción de normas justificadas. Habermas (1999, p. 36) aclara que las pretensiones universales de validez tienen que desarrollarse de manera adecuada por medio de la teoría de la argumentación. Dicho de otra manera, las acciones dialógicas que se emprendan en el entorno escolar deben recurrir a la argumentación para que puedan trascender el carácter de simples formalismos de los lineamientos de la Cátedra, pues así solo son meros contenidos que adolecen de la ausencia de acciones prácticas para la construcción de la cultura de la paz. En un mundo de vida donde la comunidad de comunicación ideal no ha tomado asidero aún en un estado de cosas, los conflictos son resueltos de otras formas, en muchas ocasiones, recurriendo a la agresión y la violencia.

Estos presupuestos deben entenderse como regla de argumentación, que se derivan del principio de contenido normativo de los presupuestos pragmáticos de la argumentación. Pero como aún no hay normas universales de validez, debe recurrirse a las normas puente para interactuar con el entorno del mundo de la vida. Esta igualmente denominada "norma necesaria" (Ruiz, 2007, pp. 4243) tiene un valor de uso en procura que quien argumenta lo debe reconocer. Este planteamiento esboza el postulado de que hay una reconstrucción hermenéutica crítica de las condiciones históricas y, además, sirve como fundamento de las normas situacionales.

Acudiendo a los argumentos de turno, en la práctica cotidiana las personas están en procura de consensos. Y por esa condición embrionaria del diálogo - por ser la única fuente normativa-, estos argumentos se convierten en normas reguladoras que, en esencia, no son normas de validez. Es por ello que se las denomina "normas puente", en cuanto comunican los saberes del mundo de la vida con las normas de validez producidas en el consenso. Estas normas deben contener el fundamento ético necesario para que los actores las reconozcan de antemano como soportes de la comunicación.

La argumentación aparece definida como el tipo de habla que los participantes tematizan las pretensiones de validez, que por alguna circunstancia son motivo de debate, ya porque sean postuladas como dudosas. La argumentación, entonces, tiene varias 
formas y posibilidades para proseguir la acción comunicativa (Habermas, 1999, p. 26); por tanto, debe contener razones conectadas sistemáticamente con la pretensión de validez, y su fuerza se mide por la pertinencia de esas razones (Habermas).

Por su parte, Ruiz (2007, p. 59) aclara que, en este continuo de racionalidad, la ética discursiva no se presenta como una meta acaba, sino mejor como una perspectiva de apertura a causa de que su fortaleza está no tanto en la racionalidad misma, sino en la acción de reconocer y compartir lo plausible. De esta manera, Ruiz da fortaleza igualmente a la propuesta de establecer una acción comunicativa por categorías en razón a que la racionalidad podría ser más consistente a medida que se evoluciona en el juicio moral, pero entendiendo que ello sucede en el proceso de aprendizaje y no como consecuencia meramente biológica de la superación de las etapas de Kohlberg.

Según lo anterior, la razonabilidad práctica es estructura de conciencia que no tiene una significación directa en acciones ni en normas de vida. Habermas (1999) afirma que entre más penetre la interpretación mítica del mundo, más fuerte es la acción totalizante de la mentalidad primitiva. Por ello, los mitos ofrecen informaciones abundantes sobre el entorno natural y social, conocimientos geográficos sobre la fauna y la flora, y detalles de las complejidades de las relaciones económicas, sociales y políticas, esto es, unas texturas de acciones sociales que desde lo cultural determinan la conciencia del sujeto (Habermas, p. 74).

En efecto, las dinámicas académicas que proponen los lineamientos de implementación de la Cátedra de la Paz analizadas en las IE de Saboyá llegan solo a este primer presupuesto ético-discusivo de la racionalidad, pero con riesgo de afectación por la falta de desarrollo moral pleno. Esta limitación provoca que los aprendizajes no sean críticos y reflexivos como el modelo se lo propone. La causa radica en que los contenidos apenas pueden inferirse en la fundamentación moral, la cual está en función de las etapas de desarrollo biológico de los aprendices. Precisamente, esos contenidos se asumen el currículo por etapas denominadas grados o cursos.

El desarrollo de los aprendizajes en cursos y la limitación de la razonabilidad condicionada genera dos problemas graves: primero, al no ofrecerse la crítica y la razón con plena facticidad, se expone a los aprendices a una colonización por las inferencias de los entornos familiares, sociales y educativos, que los determina y los detiene en el proceso de cambio cultural; segundo, como disposición plana del aprendizaje sin posibilidad de alteración, se mantiene la afectación de la comunicación y el diálogo. De esta manera, la enseñanza sería un planteamiento de contenidos que no aleja al sujeto del mundo de la vida de violencias y conflictos no resueltos.

Este es uno de los presupuestos más complejos y de mayor elaboración en los procesos de enseñanza-aprendizaje. En la medida que los docentes y orientadores puedan despertar en los aprendices la posibilidad de reflexionar y asumir una posición crítica, será posible que adopten imágenes del mundo exterior con sentido de adaptación a la cultura y de reconocimiento, tolerancia, diversidad, respeto y dignidad humana. Es entonces, la forma favorable hacia una mayor abstracción moral, que se 
comportará en nuevas acciones éticas, con las cuales, la cultura de paz prevalezca ante culturas de violencia. Pero igualmente, si la acción del agente de aprendizajes se orienta en sentido contrario, es decir, hacia la tendencia de suministrar contenido y aprendizajes simétricos, se mantendrá entonces el statu quo que se pretende superar y, como resultado, el proceso de cambio cultural estará echado a perder.

\section{Conclusiones}

La ética discursiva es facilitadora de la defensa y promoción de los derechos humanos, ya que todos sus lineamientos formales y procesuales están fundados en las máximas de la humanidad y procuran fortalecer la condición humana con un sentido de cosmología e integralidad. Esta limitación provoca que los aprendizajes no sean críticos y reflexivos como el modelo se lo propone. La causa radica en que los contenidos apenas pueden inferirse en la fundamentación moral, la cual está en función de las etapas de desarrollo biológico de los aprendices. Precisamente, esos contenidos se asumen el currículo por etapas denominadas grados o cursos.

No obstante, los intervinientes en el diálogo no llegan desprendidos de su tradición cultural, y no pretenden vaciarla con el consenso.

Lo anterior significa que, dependiendo de la trascendencia de la educación, en el sujeto se puede esperar una capacidad de comprensión del problema y, a la vez, una posición de argumentación imparcial y razonable. Por tanto, como las pretensiones deben someterse a las condiciones formales del discurso, como un postulado de validez, si falla alguno de los presupuestos de validez enunciados, el consenso no es válido.

La Cátedra de la Paz, de acuerdo con su fundamentación e implementación y con base en unos lineamientos ambiguos, está expuesta a recorrer arduo un camino colmado de múltiples escollos en los entornos sociales y académicos. Los escollos determinantes estarán en la conservación de métodos de enseñanzaaprendizaje, que conviene depurar y transformar en nuevas prácticas educativas.

Asimismo, la Cátedra requiere de un mayor compromiso de la sociedad y del Estado para fortalecer contextos no escudriñados o valorados de manera incorrecta. La institución familiar no puede continuar ausente de los procesos de enseñanzaaprendizaje. El docente está en la obligación de asumirse como agente de aprendizajes, comprometido con los aprendices, con vocación y deseo de transformación, para que así pueda generar espacios hacia la participación, el diálogo y la reflexión.

El paradigma de la verdad y los dogmas del conocimiento deben ser revaluados. Se debe impedir que las doctrinas fundamentalistas de cualquier orden y naturaleza, ya sean políticas, religiosas o filosóficas, afecten esos procesos de aprendizaje. No se pretende impedir que las personas tengan su fuero religioso o su vida espiritual, sino que esa acción personalísima, propia del atributo intelectual, debe llegar a partir de la razón y como resultado de un posicionamiento personal, no impuesto ni condicionado por los entornos culturales.

Una educación secularizada no puede enseñar doctrinas establecidas, sino que debe generar espacios para la reflexión 
sobre su existencia, su fundamentación y sus alcances en la vida de las personas. No pueden permitirse desde el marco de la Cátedra de la Paz hegemonías culturales en las distintas manifestaciones de la vida, ya sea en las artes, en las ciencias o en la conciencia de las personas.

La Cátedra de la Paz debe construir un imaginario de vida que suponga la igualdad de oportunidades para todas las personas. La aceptación y el reconocimiento no son la mera acción alter del sujeto en su relación intersubjetiva, sino que emana de un condicionamiento de comprensión de la dignidad humana de todas las personas, de la condición cosmológica de la raza, y de su compromiso y responsabilidad con el medioambiente y la naturaleza.

Todo ello se logra mediante prácticas de vida y no solamente desde el individuo, como equivocadamente se ha planteado bajo el sofisma de que la violencia está en la mente de las personas. Puede que ello sea cierto en parte, pero la existencia y la naturaleza misma es conflictiva en su accionar. Un movimiento leve o un cambio insignificante alteran el estado de quietud. Un conflicto, una pretensión o un diálogo son manifestaciones dialécticas. El problema es la posibilidad de afrontar esos cambios o movimientos de las cosas y de las acciones, para potenciarlas y convertirlas en formas de vida favorables para las personas.

Desde esa perspectiva, la paz debe pensarse de manera distinta. No hay dogmas ni doctrinas determinantes. La última palabra no está escrita ni los seres de la naturaleza tienen agotada su existencia en un momento determinado. Ello nos conduce a considerar que la paz es algo que puede ser lo dicho: tranquilidad, una vida plena o en condiciones dignificantes, o simplemente la existencia misma. Culturalmente la paz puede tener muchas manifestaciones, pero eso depende de cada comunidad y cada colectivo.

La ética que regule las formas de vida de las personas tendrá que estar libre de cargas teleológicas, axiológicas, religiosas, morales o deontológicas. Tendrá que presentarse entonces como una herramienta procesual dinamizadora de las acciones humanas, cualquiera que sea. Sus fundamentos y principios deben ser coherentes con todas las formas de pensar, ideologías, religiones y culturas. Quizá la ética discursiva tenga la aptitud y posibilidad de orientar las acciones sociales que las necesidades y los intereses de las condiciones tempo-espaciales exijan. En ello no podrá tener principios, valores, categorías o normas preestablecidas. Su acción procesual debe ser la fuente dinamizadora de creación de esas normas, según el momento histórico y el lugar de producción.

\section{Referencias}

Acodesi -Asociación de Colegios Jesuitas de Colombia-. (2003). Hacia una educación para la paz. Estado del arte. Acodesi. Bogotá: Kimpres. Disponible en: http://www.acodesi. org.co/es/images/stories/textosrecomendados/ Hacia\%20una\%20Educacion\%20para\%20 la\%20Paz $\% 20$-Estado\%20del\%20Arte-.pdf

Cohen, J. y Arato, A. (2000). Sociedad civil y teoría política. Ciudad de México: Fondo de Cultura Económica.

Constitución Política de Colombia. (1991). Disponible en: www.corteconstitucional.gov. $\underline{\text { co/?bTy }}$ 
Freire, P. (2006). Pedagogía de la autonomía sobre saberes necesarios para la práctica educativa (2 ed.). Buenos Aires: Siglo XXI editores.

Galtung, J. (2003). Violencia cultural. Gernika Gogoratuz, Documento 14. Disponible en: https://www.gernikagogoratuz.org/web/ uploads/

Garcés, G. J. (s.f). Hacia Una pedagogía del conocimiento. Revista Educación y Pedagogía (12 y 13), 337-350. Recuperado el 22 de mayo de 2017, de file://C:/Users/Admin/ Downloads/6227-17063-1-PB.pdf

Giménez R, C. (2008). Interculturalismo. Elaboraciones y propuestas desde un equipo universitario teórico-aplicado. En G. Mantovani (coord.). Intercultura e Mediazione. Teorie ed esperience (pp. 149-169). Roma: Carocci Editori. Disponible en: https://www.uam. es/otroscentros/imedes/docs/publi/CGR_1 sobre Interculturalidad.pdf

Habermas, J. (1994). Conciencia moral y acción comunicativa. Barcelona: Planeta de Agostini.

\section{(1999). Acción Comunicativa}

I-Racionalidad de la Acción y racionalización social. (1 ed.) Madrid: Taurus.

Madrid: Editorial Trotta.

. (2010). Acción comunicativa.

Barcelona: Editorial Trotta.

Jares, X. (2002). Aprender a convivir. Revista Interuniversitaria de Formación del Profesorado, (44), pp. 79-92. http://www. redalyc.org/articulo.oa?id $=27404405$

López B, M. (2011). Teorías para la paz y perspectivas ambientales del desarrollo como diálogos imperfectos. Revista Luna Azul, (33), pp. 85-96. Disponible en: http://www.redalyc. org/comocitar.oa? id=321727235008

MEN -Ministerio de Educación Nacional-. (2001). Informe nacional sobre el desarrollo de la educación en Colombia. 46 ${ }^{\mathrm{a}}$ Conferencia Internacional de Educación (CIE). Bogotá. Disponible en: http://www.ibe.unesco.org/ International/ICE/natrap/Colombia.pdf

Reyes, F., Lozano, R., Vargas, M., Bayona, A., y Molina, A. (1998). Lineamientos curriculares para el área de Ética y Valores Humanos. Bogotá: MEN. Disponible en: http://www.oei. es/historico/valores2/boletin6.htm\#tabla

RodríguezÁ,G.(2016).EducaciónéticayCátedra de la Paz. Revista de Educación Fundación Convivencia, ene-abr, pp. 6-13. Disponible en: http://www.fundacionconvivencia.org/Revista. $\underline{\text { shtml} \text { ?apc }=h-x x-1-\& x=381}$

Ruiz S, A. (2007). El diálogo que somos: ética discursiva y educación. Bogotá: Cooperativa Editorial Magisterio. Disponible en: https://www.academia.edu/4367486/El di\%C3\%A1logo_que somos._\%C3\%89tica discursiva_y_educaci $\% \mathrm{C} 3 \% \mathrm{~B} 3 \mathrm{n}$

Sánchez, M. (2016). Educación para la cultura de paz: una aproximación psicopedagógica (2a ed.). Bogotá: Ediciones USTA.

Valencia G, A. (2004). Ética de la discusión. Cuadernos para la reflexión. Disponible en: $\quad$ http://valenciad.com/Conferencias/ ComunicEticaDiscus.pdf

Zuleta P, M. (2006). La violencia en Colombia: avatares de la construcción de un objeto de estudio. Nómadas (25), pp. 54-69. Disponible en: http://www.redalyc.org/articulo. $\underline{\text { oa? } \mathrm{id}=105115224006}$ 